Article

\title{
In Vitro Investigation of Thiol-Functionalized Cellulose Nanofibrils as a Chronic Wound Environment Modulator
}

\author{
Anna Blasi-Romero ${ }^{1}$, Carlos Palo-Nieto ${ }^{1}$, Corine Sandström ${ }^{2} \mathbb{D}$, Jonas Lindh ${ }^{1} \mathbb{D}$, Maria Strømme ${ }^{1} \mathbb{D}$ and \\ Natalia Ferraz ${ }^{1, *(1)}$
}

1 Nanotechnology and Functional Materials, Department of Material Science and Engineering, Uppsala University, Box 35, 75103 Uppsala, Sweden; anna.blasi@angstrom.uu.se (A.B.-R.); carlos.nieto@angstrom.uu.se (C.P.-N.); jonas.lindh@angstrom.uu.se (J.L.); maria.stromme@angstrom.uu.se (M.S.)

2 Department of Molecular Sciences, Swedish University of Agricultural Sciences, Box 7015, 75007 Uppsala, Sweden; corine.sandstrom@slu.se

* Correspondence: natalia.ferraz@angstrom.uu.se

Citation: Blasi-Romero, A.;

Palo-Nieto, C.; Sandström, C.; Lindh, J.; Strømme, M.; Ferraz, N. In Vitro Investigation of Thiol-Functionalized Cellulose Nanofibrils as a Chronic Wound Environment Modulator. Polymers 2021, 13, 249. https:// doi.org/10.3390/polym13020249

Received: 8 December 2020

Accepted: 10 January 2021

Published: 13 January 2021

Publisher's Note: MDPI stays neutral with regard to jurisdictional clai$\mathrm{ms}$ in published maps and institutional affiliations.

Copyright: (C) 2021 by the authors. Licensee MDPI, Basel, Switzerland. This article is an open access article distributed under the terms and conditions of the Creative Commons Attribution (CC BY) license (https:// creativecommons.org/licenses/by/ $4.0 /)$.

\begin{abstract}
There is currently a huge need for new, improved therapeutic approaches for the treatment of chronic wounds. One promising strategy is to develop wound dressings capable of modulating the chronic wound environment (e.g., by controlling the high levels of reactive oxygen species (ROS) and proteases). Here, we selected the thiol-containing amino acid cysteine to endow wood-derived cellulose nanofibrils (CNF) with bioactivity toward the modulation of ROS levels and protease activity. Cysteine was covalently incorporated into CNF and the functionalized material, herein referred as cys-CNF, was characterized in terms of chemical structure, degree of substitution, radical scavenging capacity, and inhibition of protease activity. The stability of the thiol groups was evaluated over time, and an in vitro cytotoxicity study with human dermal fibroblasts was performed to evaluate the safety profile of cys-CNF. Results showed that cys-CNF was able to efficiently control the activity of the metalloprotease collagenase and to inhibit the free radical DPPH (1,1-Diphenyl-2-picrylhydrazyl radical), activities that were correlated with the presence of free thiol groups on the nanofibers. The stability study showed that the reactivity of the thiol groups challenged the bioactivity over time. Nevertheless, preparing the material as an aerogel and storing it in an inert atmosphere were shown to be valid approaches to increase the stability of the thiol groups in cys-CNF. No signs of toxicity were observed on the dermal fibroblasts when exposed to cys-CNF (concentration range $0.1-0.5 \mathrm{mg} / \mathrm{mL}$ ). The present work highlights cys-CNF as a promising novel material for the development of bioactive wound dressings for the treatment of chronic wounds.
\end{abstract}

Keywords: nanocellulose; wound healing; proteases; reactive oxygen species; cysteine; antioxidant properties

\section{Introduction}

Cutaneous wound healing is a well-orchestrated process consisting of four overlapping phases: hemostasis, inflammation, proliferation, and remodeling. Most skin wounds heal within 2-3 weeks, however, imbalances in the wound healing phases can lead to nonhealing chronic wounds [1]. Chronic wounds remain in the inflammatory phase, where elevated levels of reactive oxygen species (ROS), pro-inflammatory cytokines, and degradative proteases result in reduced concentrations of growth factors and proteinase inhibitors, and an imbalance in the wound equilibrium [2]. Diabetes and vascular insufficiency are the main underlying causes of non-healing wounds, with systemic factors such as advanced age or a compromised immune system also contributing to poor wound-healing. The incidence of chronic wounds has dramatically increased in recent years, now reaching epidemic proportions [3]. Presently, most of the widely used wound dressings only provide an optimal local healing milieu (i.e., they protect the wound from further trauma, provide 
moisture, and adsorb excess exudate) [4]. To improve the treatment of chronic wounds, it has been proposed that new types of wound-healing therapies will be required, with the aim of obtaining bioactive dressings that stimulate local cells to migrate and proliferate, stimulate, and guide extracellular matrix deposition, modulate protease activity, and/or neutralize free radicals [4].

Nanocellulose is emerging as an interesting material for biomedical applications such as tissue engineering, drug delivery, and wound care $[5,6]$. Nanocellulose consists of cellulose fibrils or crystallites with dimensions in the nanoscale and is obtained from a diversity of sources such as wood, algae, bacteria, and tunicates [7]. Wood-derived cellulose nanofibrils (CNF) comprise individual fibrils that are 2-10 $\mathrm{nm}$ in diameter and several micrometers in length, typically forming 20-60 nm thick aggregates [8]. Characteristics such as being a renewable material, not being of animal origin, having tuneable properties in terms of surface chemistry, aspect ratio and form, and being produced in a process that can easily be scaled-up industrially have contributed to the increased interest in using CNF for biomedical applications $[5,9]$. CNF have been described as a promising material for the treatment of wounds $[5,10,11]$. Authors have highlighted the physicochemical properties of the material and the absence of cytotoxicity as beneficial characteristics for employing CNF films, aerogels, and gel suspensions as wound dressings [12-14]. Moreover, clinical studies have shown encouraging results when using CNF films on skin graft donor sites [15,16]. Our group has demonstrated the in vitro and in vivo wound healing properties of an ion-crosslinked CNF hydrogel [17-19] together with the evaluation of its antibacterial properties [20] and the possibility of using the hydrogel as a drug delivery dressing [21].

In the present work, we selected the amino acid cysteine as an active molecule to endow $\mathrm{CNF}$ with bioactivity and for the first time investigate the potential of the functionalized CNF material to modulate the chronic wound environment in vitro. It is believed that addressing the biochemical imbalances typically found in chronic wounds will aid in the resolution of these hard-to-heal wounds. Thus, by targeting the excess of ROS and the high level of metalloprotease activity, it may be possible to restore basal levels of growth factors, promote the restitution of the proper balance between degradation and formation of new tissue, and help overcome the prolonged inflammatory phase observed in chronic wounds $[22,23]$. The radical scavenging properties of cysteine and its metal chelating ability [24,25], make this amino acid an excellent candidate molecule to be used in the development of wound dressings capable of interacting with the biochemical environment of chronic wounds.

In this study, cysteine was covalently incorporated into CNF and the functionalized material was characterized in terms of chemical structure and degree of substitution. The radical scavenging properties and the capacity of the material to inhibit metalloprotease activity were investigated. Furthermore, the stability of the thiol groups in cys-CNF and its bioactivity were evaluated over time. Finally, the safety profile of the thiol-functionalized $\mathrm{CNF}$ was investigated in an in vitro cytotoxicity study with human dermal fibroblasts.

\section{Materials and Methods}

\subsection{Chemicals and Reagents}

Carboxylated-CNF, provided by RISE Bioeconomy (Stockholm, Sweden), was produced from commercial never-dried bleached sulfite softwood dissolving pulp (lignin content $<1.5 \%$, xylose $<1.7 \%$, mannose $<1.8 \%$, Domsjö Fabriker AB, Örnsköldsvik, Sweden) by 2,2,6,6-tetramethylpiperidine-1-oxyl (TEMPO)-mediated oxidation. L-cysteine methyl ester hydrochloride, $N$-(3-dimethyolaminopropyl)- $N$ '-ethylcarbodiimide hydrochloride (EDC), $N$-hydroxysuccinimide (NHS), collagenase from Clostridium histolyticum, and calcein-AM were obtained from Sigma Aldrich (St. Louis, MO, USA). Fetal bovine serum (FBS), penicillinin, streptomycin, 5,5-dithio-bis-(2-nitrobenzoic acid) (DTNB), EnzChek ${ }^{\mathrm{TM}}$ Gelatinase/Collagenase Assay Kit, Pierce ${ }^{\mathrm{TM}}$ Bradford Protein Assay Kit, DMEM:F12 medium, fetal bovine serum, and presto blue cell viability reagent were obtained from Ther- 
moFisher Scientific (Waltham, MA, USA). 1,1-Diphenyl-2-picrylhydrazyl radical (DPPH) was purchased from Santa Cruz Biotechnology (Dallas, TX, USA).

\subsection{Covalent Incorporation of Methyl Cysteine to Cellulose Nanofibrils}

L-cysteine methyl ester was covalently incorporated to carboxylated CNF (c-CNF, carboxyl group content $1300 \mu \mathrm{mol} / \mathrm{g}$ dry CNF) via EDC/NHS coupling (Figure 1). Briefly, $100 \mathrm{~g}$ of c-CNF suspension corresponding to $1 \mathrm{~g}$ of dried cellulose was dispersed in $50 \mathrm{~mL}$ of deionized water and $5 \mathrm{~mL}$ of aqueous solution containing $180 \mathrm{mg}$ of NHS and $290 \mathrm{mg}$ of EDC (corresponding to $1.2 \mathrm{mmol}$ of NHS/EDC per mol of carboxyl group in CNF) were added under stirring, followed by the addition of $10 \mathrm{~mL}$ of L-cysteine methyl ester aqueous solution. Two different molar ratios cysteine: $\mathrm{COOH}$ were used in the synthesis, corresponding to 6 and 20 equivalents of cysteine with respect to the carboxyl groups in c-CNF. The reaction mixture was stirred for $24 \mathrm{~h}$ at $\mathrm{pH} 5$ and room temperature. For purification, three cycles of centrifugation ( $30 \mathrm{~min}$ at $3380 \times g$ ) were carried out, followed by dialysis against deionized water until the conductivity in water was $<0.005 \mathrm{mS} / \mathrm{cm}^{2}$.
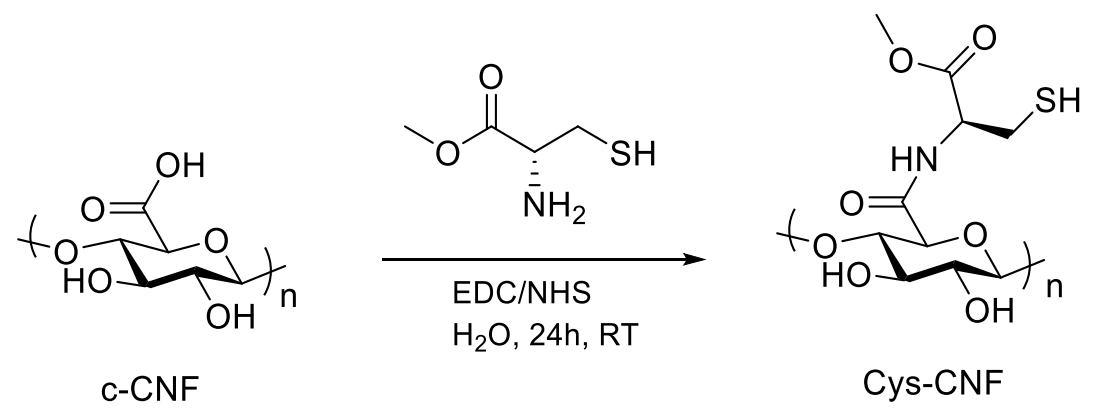

Figure 1. Reaction scheme of the chemical modification of carboxylated cellulose nanofibrils (c-CNF) with L-cysteine methyl ester to obtain cysteine-functionalized CNF (cys-CNF).

\subsection{Material Characterization}

\subsubsection{Characterization of the Molecular Structure}

The chemical structure of cys-CNF was characterized by solid-state nuclear magnetic resonance (NMR). The NMR spectra were obtained on a Bruker Avance III $600 \mathrm{MHz}$ spectrometer (Bruker, Billerica, MA, USA) using a double-resonance $4 \mathrm{~mm}\left({ }^{1} \mathrm{H} \&{ }^{19} \mathrm{~F}\right) /\left({ }^{15} \mathrm{~N}-{ }^{31} \mathrm{P}\right) \mathrm{CP}-\mathrm{MAS}$ probe and $4 \mathrm{~mm} \mathrm{ZrO}_{2}$ rotors. The ${ }^{13} \mathrm{C}$ cross-polarization $(\mathrm{CP})$ magic angle spinning (MAS) NMR spectra were recorded at a spinning frequency of $12 \mathrm{KHz}$, a contact time of 1-2 ms and a repetition delay of 3-5 s. The experiments were performed at $298 \mathrm{~K}$.

\subsubsection{Degree of Substitution}

The cysteine content of cys-CNF was determined by elemental analysis of total sulfur content. For this, cys-CNF freeze-dried samples were submitted to MEDAC Ltd., analytical and chemical consultancy services (Cobham, UK), where a Thermo FlashEA ${ }^{\mathrm{R}} 1112$ instrument was used for sulfur quantification. The weight percentage of sulfur in cys-CNF was converted to mmol cysteine/g CNF [26] and the degree of substitution (DS) was calculated as the cysteine content (mmol/g CNF) per number of carboxyl groups in the starting material c-CNF (1.3 mmol/g CNF).

\subsubsection{Thiol Group Content}

The thiol group content was quantified by the Ellman assay. Briefly, $2.5 \mathrm{~mL}$ of reaction buffer ( $0.1 \mathrm{M}$ sodium phosphate, $\mathrm{pH}$ 8.0, containing $1 \mathrm{mM}$ EDTA) was mixed with $250 \mu \mathrm{L}$ of cys-CNF suspension $(0.05 \mathrm{wt} \%)$ and $50 \mu \mathrm{L}$ of DTNB solution $(4 \mathrm{mg} / \mathrm{mL}$ in reaction buffer). After $15 \mathrm{~min}$, the absorbance at $412 \mathrm{~nm}$ was measured using a spectrophotometer (UV-1800, Shimadzu, Kyoto, Japan). The number of thiol groups in the CNF samples was calculated using a L-cysteine methyl ester standard curve and expressed as mmol SH/g CNF. 


\subsection{Radical Scavenging Capacity}

Free radical scavenging capacity was evaluated with DPPH by measuring the decrease in absorbance of the radical at $517 \mathrm{~nm}$ after incubation with the CNF materials. In brief, $1.2 \mathrm{~mL}$ of CNF suspension in water (containing $0.5 \mathrm{mg}, 2 \mathrm{mg}$, and $5 \mathrm{mg}$ of dry CNF materials) was mixed with $10.8 \mathrm{~mL}$ of DPPH ( $0.2 \mathrm{mM}$ in methanol). After $90 \mathrm{~min}$ incubation time protected from direct light, reaction tubes were centrifuged to spin down the CNF materials and the absorbance of the supernatant was measured at $517 \mathrm{~nm}$ with a plate reader (TECAN infinite M200, Männedorf, Switzerland). Radical scavenging capacity was expressed as percentage of DPPH inhibition according to Equation (1):

$$
\text { Radical scavenging capacity ( \% DPPH inhibition })=\left(1-\frac{A_{S}}{A_{R}}\right) * 100,
$$

where $A_{S}$ is the absorbance at $517 \mathrm{~nm}$ of the DPPH solution after incubation with the CNF samples and $A_{R}$ is the absorbance at $517 \mathrm{~nm}$ of the DPPH reference solution (i.e., incubated alone).

\subsection{Evaluation of the Material Interactions with the Metalloprotease Collagenase}

Collagenase from Clostridium histolyticum was selected as a model protein to investigate the interaction of cys-CNF with metalloproteases. Aqueous suspensions $(0.7 \mathrm{~mL})$ of the CNF materials containing $0.1 \mathrm{mg}, 0.2 \mathrm{mg}$, and $3.5 \mathrm{mg}$ of dry cellulose were mixed with collagenase in reaction buffer $\left(0.5 \mathrm{M}\right.$ Tris- $\mathrm{HCl}, 1.5 \mathrm{M} \mathrm{NaCl}, 50 \mathrm{mM} \mathrm{CaCl}_{2}$, and $2 \mathrm{mM}$ sodium azide, $\mathrm{pH} 7.6$ ) at a final protein concentration of $10 \mu \mathrm{g} / \mathrm{mL}$ in a final volume of $1.5 \mathrm{~mL}$. The mixture was incubated for $24 \mathrm{~h}$ at $37^{\circ} \mathrm{C}$ under agitation ( $\left.400 \mathrm{rpm}\right)$. Afterward, reaction tubes were centrifuged to spin down the fibers and the supernatant was collected to determine the collagenase activity and concentration.

\subsubsection{Evaluation of Protease Inhibition}

The EnzChek ${ }^{\mathrm{TM}}$ Collagenase Assay Kit was used to quantify the activity of collagenase after incubation with the materials. The assay was performed as indicated by the manufacturer. Briefly, $20 \mu \mathrm{L}$ of fluorescein conjugate-gelatin ( $\mathrm{DQ}^{\mathrm{TM}}$ Gelatin, $0.5 \mathrm{mg} / \mathrm{mL}$ ) was added to $100 \mu \mathrm{L}$ of reaction buffer $(0.5 \mathrm{M}$ Tris- $\mathrm{HCl}, 1.5 \mathrm{M} \mathrm{NaCl}, 50 \mathrm{mM} \mathrm{CaCl}$, and $2 \mathrm{mM}$ sodium azide, $\mathrm{pH}$ 7.6) mixed with $80 \mu \mathrm{L}$ of CNF-incubated collagenase solution. The increase in fluorescence signal (excitation/emission at $485 / 530 \mathrm{~nm}$ ), as a result of substrate cleavage by the collagenase, was measured from minute 0 to 120 with a plate reader (TECAN infinite M200, Männedorf, Switzerland). To calculate the inhibition of collagenase activity, the $30 \mathrm{~min}$ time point was selected and the fluorescence intensity of the CNF-incubated collagenase samples was compared to the fluorescence intensity of the collagenase control according to Equation (2):

$$
\text { Inhibition collagenase activity }(\%)=\left(1-\frac{\mathrm{F}_{\text {sample }}}{\mathrm{F}_{\text {control }}}\right) * 100 \text {, }
$$

where $\mathrm{F}$ is fluorescence intensity (a.u.) at the $30 \mathrm{~min}$ time point.

\subsubsection{Evaluation of Protease Entrapment}

The Bradford assay was used for protein quantification. Simply, $100 \mu \mathrm{L}$ of CNFincubated collagenase was mixed with $100 \mu \mathrm{L}$ of Bradford reagent in a transparent 96 well plate. Following the protocol from the manufacturer, the plate was shacked for $30 \mathrm{~s}$ and, after $10 \mathrm{~min}$ incubation at room temperature, absorbance was measured at $595 \mathrm{~nm}$ with a plate reader (TECAN infinite M200, Männedorf, Switzerland). Protein entrapment was expressed as percentage of collagenase in solution after incubation with CNF over the content of the protein in the control solution, as expressed in Equation (3):

$$
\text { Protein Entrapment }(\%)=\left(1-\frac{A_{S}}{A_{R}}\right) * 100
$$


where $A_{S}$ and $A_{R}$ are the absorbance values at $595 \mathrm{~nm}$ of the sample and of the control solution, respectively.

\subsection{3. $\mathrm{Zn}^{2+}$ Binding Assay}

With similar conditions as in the collagenase inhibition experiment, water suspension of the CNF materials ( $5 \mathrm{mg}$ dry content) were mixed and incubated with $0.1 \mathrm{mM}$ zinc acetate in a final volume of $3 \mathrm{~mL}$. The mixture was left in a shaking plate at $37^{\circ} \mathrm{C}$ for $24 \mathrm{~h}$. Then, fibers were spun down and the zincon assay was performed to quantify the remaining zinc in the supernatant. Briefly, $25 \mu \mathrm{L}$ of sample (supernatant) was mixed with $950 \mu \mathrm{L}$ of $53 \mathrm{mM}$ borate buffer, $\mathrm{pH}$ 9; and $25 \mu \mathrm{L}$ of $1.6 \mathrm{mM}$ zincon (2-carboxy-2'-hydroxy$5^{\prime}$-sulfoformazyl-benzene) solution were added to the mixture. The absorbance at $620 \mathrm{~nm}$ was measured $5 \mathrm{~min}$ later. Zinc content was expressed as a percentage of the reference solution (i.e., where the CNF suspension was replaced by water).

\subsection{Material Stability over Time}

The thiol content and the radical scavenging properties of the cys-CNF suspension were measured by the Ellman assay and the DPPH assay, respectively, over a time period of 30 days to evaluate the stability of the thiol group in the cys-CNF suspension and the correlation to its radical scavenging capacity. The material was kept at $4{ }^{\circ} \mathrm{C}$ in three different storage conditions: suspensions in a closed container, aerogels prepared by freeze-drying, and suspensions stored under an inert atmosphere. The Ellman assay and the DPPH assay were conducted following the protocols described in Sections 2.3 and 2.4, respectively.

\subsection{Cell Studies}

\subsubsection{Cell Culture}

Adult human dermal fibroblasts (hDF) (primary cells from the European Collection of Authenticated Cell Cultures (ECACC, Salisbury, England) were cultured in DMEMF12 medium supplemented with $10 \% v / v$ fetal bovine serum, $100 \mathrm{U} / \mathrm{mL}$ penicillin, and $100 \mu \mathrm{g} / \mathrm{mL}$ streptomycin. Cells were cultured at $37{ }^{\circ} \mathrm{C}$ and $5 \% \mathrm{CO}_{2}$ in a humidified atmosphere and passaged at $80 \%$ confluency.

\subsubsection{Cytotoxicity Assessment}

The cytotoxicity of cys-CNF was assessed by exposing hDF monolayers to suspensions of cys-CNF (1:20). Concentrations from 0.1 to $1 \mathrm{mg} / \mathrm{mL}$ in cell culture medium were prepared from $10 \mathrm{mg} / \mathrm{mL}$ stock suspension in water the day of the experiment. A control experiment showed that the dilution of cell culture medium due to the water content of the CNF stock suspension did not significantly affect the cell viability.

$\mathrm{hDF}$ cells (passage numbers 10-16) were seeded in a 96 well-plate at a density of $4.8 \times 10^{3}$ cells/well and after $24 \mathrm{~h}$ of culture, they were exposed to the cys-CNF suspensions ( $200 \mu \mathrm{L} /$ well) and cultured for another $24 \mathrm{~h}$. Non-treated cells were used as the negative control and cells exposed to 5\% DMSO in cell culture medium were the positive control. $\mathrm{c}-\mathrm{CNF}$ was also included in the toxicity assessment in the same concentration range as cys-CNF.

Cellular metabolic activity was measured with the presto blue (PB) assay after $24 \mathrm{~h}$ of exposure to the CNF materials. Cell culture media were removed from the cell culture wells and cells were carefully washed with warm PBS. Thereafter, $200 \mu \mathrm{L}$ of PB reagent diluted 1:10 in cell culture media were added to each well and incubated for $90 \mathrm{~min}$ at $37^{\circ} \mathrm{C}$, and $5 \% \mathrm{CO}_{2}$ in a humidified atmosphere. Aliquots of $100 \mu \mathrm{L}$ were transferred to a black 96-well plate and fluorescence was measured at $560 \mathrm{~nm}$ excitation and $590 \mathrm{~nm}$ emission wavelengths using a plate reader (Tecan infinite M200, Männedorf, Switzerland). Cell metabolic activity was used as an indicator of cell viability and the results were expressed as the percentage of the negative control. The interaction of the CNF samples with the PB reagent was evaluated by applying the same protocol as above, but in the absence of cells and the results showed no interference of the samples with the PB assay. 
Cell viability and morphology were also assessed by microscopic observations of calcein-AM stained cells. Briefly, cell media were removed from the wells, and $100 \mu \mathrm{L}$ of calcein-AM $(0.1 \% v / v$ in PBS) were added to each well. After 15 min incubation time in the cell incubator, cells were imaged with a fluorescence microscope (Nikon Eclipse TE2000-U, Tokyo, Japan).

\subsection{Statistical Analysis}

All data are presented as mean \pm standard error of the mean from at least three independent experiments, each with triplicate sampling. Statistical analyses were performed using GraphPad Prism software. Differences between groups were evaluated by one-way analysis of variance (ANOVA), followed by Dunnett's test for pairwise comparisons. A $t$-test was used for paired comparison of the two treatment groups. The differences were considered statistically significant when the $p$ value was $<0.05$.

\section{Results and Discussion}

\subsection{Material Characterization}

The broad spectrum of possible chemical modifications of cellulose opens up the possibility of endowing the material with novel properties. Typically, surface chemical modifications of cellulose are employed during the production of CNF to introduce charged groups and facilitate the defibrillation process. Furthermore, post-production chemical modifications of CNF can take advantage of these introduced charged groups to explore new functionalization and obtain CNF materials with added value [27]. In the present work, we investigated the possibility of obtaining a bioactive CNF material by thiolfunctionalization of the fibrils, with the ultimate aim of modulating the high levels of ROS and metalloproteinases found in hard-to-heal wounds. The carboxyl groups in the starting CNF, introduced by TEMPO-oxidation pretreatment of the wood pulp, were targeted to react with the amine groups of the thiol-amino acid cysteine via the EDC/NHSmediated coupling.

The covalent incorporation of cysteine to CNF was investigated by $\mathrm{CP} / \mathrm{MAS}{ }^{13} \mathrm{C}$ NMR spectroscopy. The ${ }^{13} \mathrm{C}-\mathrm{NMR}$ spectrum of cys-CNF is displayed in Figure 2, together with the spectrum of c-CNF, cysteine, and cystine (cysteine oxidized dimer) as references. The signals at $24 \mathrm{ppm}$ in the cys-CNF spectrum could be attributed to the $C \beta$ in cysteine while the signals around 37 and 43 ppm were assigned to the methylene groups in cystine. The signals from the $\mathrm{C} \alpha$ and OMe carbons in cysteine and cystine were found to merge around $54 \mathrm{ppm}$. The broadening of the signals from cysteine and cystine in cys-CNF indicates that these two compounds interacted with $\mathrm{c}-\mathrm{CNF}$, reducing the motions of the carbons. Close inspection of the 170-180 ppm region showed a broad shoulder upfield to the signal of the carboxyl resonance of CNF. This was tentatively assigned to the carbonyl of the ester in cysteine and cystine and to the amide linkages formed between the amino acid and c-CNF. Similar effects have been shown in previous studies on cellulose-amino acid copolymers [28,29]. Altogether, the analysis of the solid-state NMR spectra indicated the presence of covalently bound cysteine in cys-CNF and the formation of its oxidized dimer cystine. 


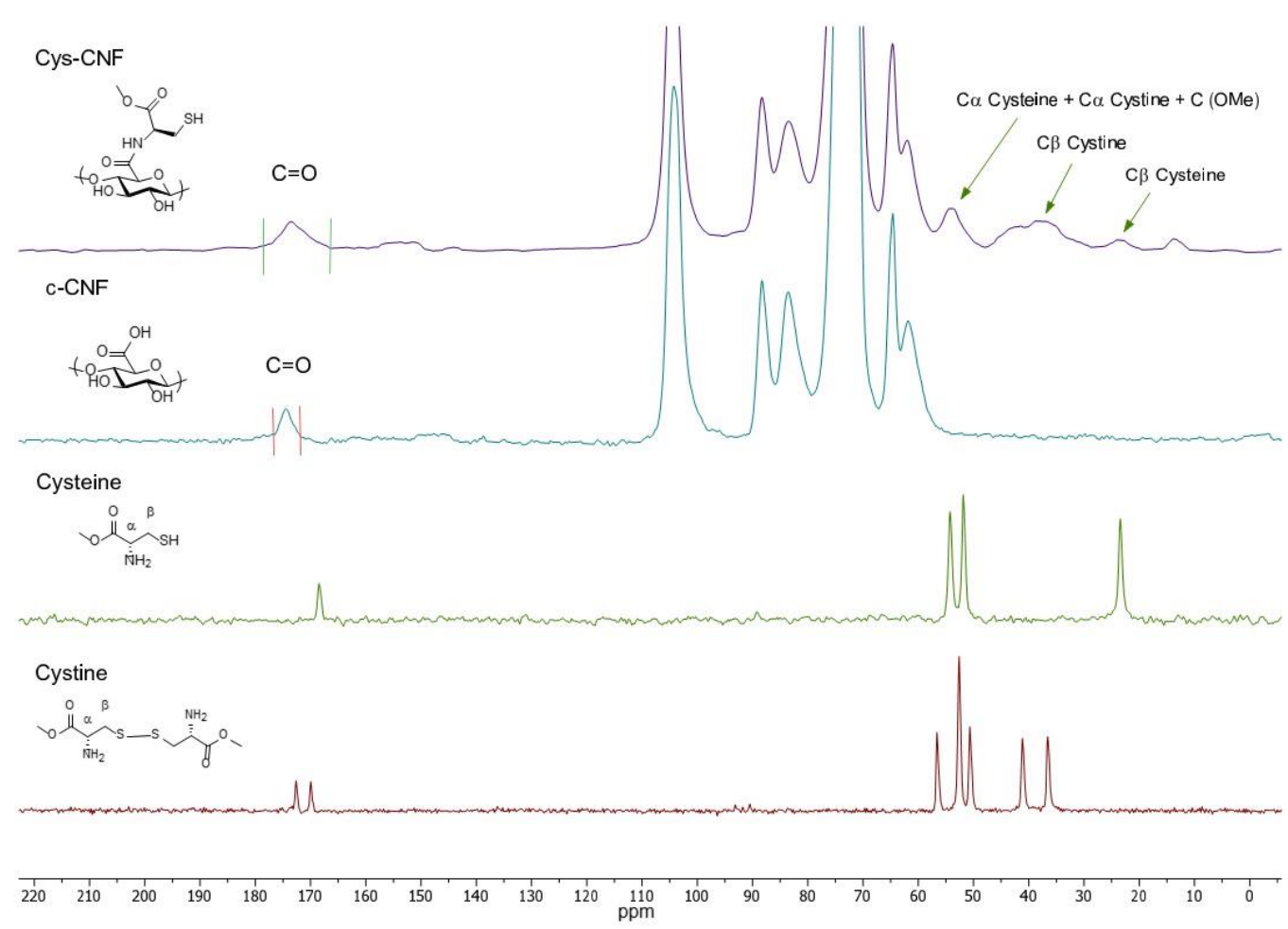

Figure 2. Solid-state nuclear magnetic resonance (NMR) spectra of cys-CNF and the references c-NFC, cysteine, and cystine.

The cysteine-functionalization of CNF was further investigated by elemental analysis, confirming and quantifying the presence of cysteine in the modified CNF material. Elemental analysis indicated that increasing the molar ratio in the reaction did not result in a significant increase in the number of incorporated cysteine (Table 1), obtaining a substitution between $50-60 \%$ of the carboxyl groups in the starting material. The cys-CNF material was also analyzed by scanning electron microscopy (SEM) with energy dispersive spectroscopy (EDS), revealing a homogeneous distribution of sulfur on the material surface (Figure S1, Supplementary Materials).

Table 1. Cysteine content, degree of substitution, and free-thiol content of the cys-CNF materials obtained using two different molar reaction ratios.

\begin{tabular}{ccccc}
\hline $\begin{array}{c}\text { Molar Reaction } \\
\text { Ratio }^{\mathbf{1}}\end{array}$ & $\begin{array}{c}\text { Cysteine } \\
\text { Content } \\
\text { (mmol/g CNF) }^{\mathbf{m}^{2}}\end{array}$ & $\begin{array}{c}\text { Degree of } \\
\text { Substitution }\end{array}$ & $\begin{array}{c}\text { Thiol Content } \\
\text { (mmol/g CNF) }^{\mathbf{4}}\end{array}$ & $\begin{array}{c}\text { Thiol/Sulfur } \\
\text { (\%) }\end{array}$ \\
\hline $1: 6$ & $0.71 \pm 0.07$ & $0.54 \pm 0.05$ & $0.14 \pm 0.02$ & 20 \\
$1: 20$ & $0.78 \pm 0.04$ & $0.60 \pm 0.05$ & $0.20 \pm 0.03$ & 26 \\
\hline
\end{tabular}

$\overline{{ }^{1} \mathrm{COOH}: c y s t e i n e .}{ }^{2}$ Determined by elemental analysis of sulfur content. ${ }^{3}$ Number of cysteine (mmol/g CNF) per number of carboxyl groups in the starting material c-CNF $(1.3 \mathrm{mmol} / \mathrm{g} \mathrm{CNF}) .{ }^{4}$ Determined by the Ellman assay.

The potential ability of the cys-CNF to modulate the chronic wound environment is expected to depend on the presence of free thiol groups and therefore the cys-CNF was further characterized in terms of free thiol content by the Ellman assay. Results showed that the number of free thiols corresponded to $20-26 \%$ of the total sulfur content in cys-CNF (Table 1). The formation of cystine is most probably the reason behind the decrease in thiol groups with respect to the total sulfur content. The presence of cystine in cys-CNF was observed in the NMR spectrum (Figure 2) and the oxidized dimer could have formed during the synthesis step where free cysteines reacted with already immobilized cysteine molecules or during the dialysis steps as a result of the reaction between neighboring immobilized cysteines forming disulfide bonds. 


\subsection{Radical Scavenging Activity}

High levels of ROS in chronic wounds have been associated with several adverse effects (e.g., cell damage, inhibition of cell migration, inactivation of metalloproteinase inhibitors, and recruitment of more inflammatory cells into the wound), all contributing to the delayed healing process [30]. Thus, wound dressings with antioxidant properties may modulate the ROS levels in the wound bed and help to reactivate the healing of chronic wounds [31,32].

The antioxidant activity of cysteine is well documented, both in proteins and as free amino acid [25]. Authors have shown that cysteine is one of the most potent antioxidant amino acids, acting as a free radical scavenger and also as a metal chelator [25]. Here, the results indicated that the covalently bound cysteine endowed CNF with radical scavenging activity, with the functionalized CNF material showing a concentration-dependent DPPH inhibition (Figure 3a) while c-CNF did not inhibit DPPH radical activity (data not shown). No statistically significant differences were found between the radical scavenging activities of cys-CNF (1:6) and cys-CNF (1:20).

(a)

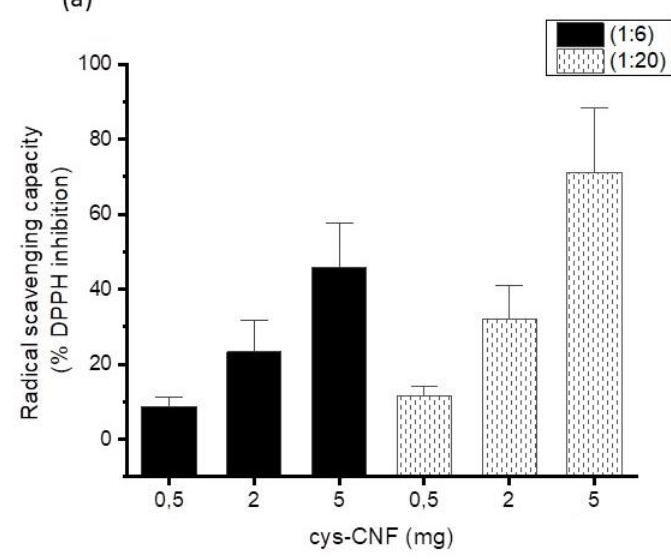

(b)

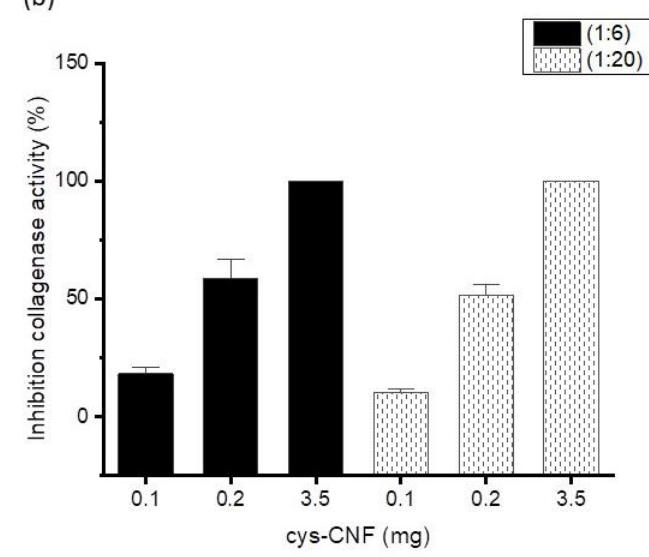

Figure 3. Cys-CNF activity as (a) radical scavenging capacity), (b) inhibition of collagenase activity. Data are presented as mean \pm standard error of the mean of at least three independent experiments. No statistically significant differences were found between the radical scavenging activities of cys-CNF (1:6) and cys-CNF (1:20), nor between the cys-CNF (1:6) and cys-CNF (1:20) collagenase-inhibition capacities.

The antioxidant properties of cellulose-based wound dressings have been previously investigated [33-37]. The ability of the commercially available carboxymethylcellulosebased dressing Aquacel ${ }^{\mathrm{TM}}$ to inhibit ROS activity was investigated by Moseley et al., showing that the dressing presented an antioxidant potential most probably based on the restriction of the movement of the free radical (i.e., the ROS molecules can be entrapped into the viscous mesh-network of the dressing) and as a result, they are not able to interact with biological targets $[33,34]$. Thus, the antioxidant properties of the carboxymethylcellulosebased dressing can be classified as passive, rather than an intrinsic antioxidant capacity of the material. Moreover, when Cullen et al. tested the antioxidant properties of carboxymethylcellulose with the DDPH assay, no activity was found confirming the lack of intrinsic antioxidant activity of the carboxymethylated cellulose [37], a result that is in line with our finding that c-CNF alone lacks free radical scavenging activity. Here, we showed that the covalent functionalization of the cellulose nanofibers with cysteine is a promising approach to obtain a nanocellulose-based dressing capable of directly reacting with free radicals. Another strategy to endow nanocellulose-based dressings with antioxidant properties is to incorporate antioxidant compounds within the fiber matrix, allowing the dressing to act as a drug delivery system $[35,36]$. This approach presents the challenge of tailoring the drug load and release, while with a cys-CNF based wound dressing, the 
antioxidant capacity may be easier to control, since the antioxidant properties originate from the dressing matrix itself.

\subsection{Interactions with the Metalloprotease Collagenase}

The elevated activity of metalloproteinases found in chronic wounds causes excessive extra cellular matrix degradation, alteration of cytokine profile, and low levels of growth factors, resulting in the delay or absence of wound closure [22,38]. Several therapies based on the inhibition of metalloproteinase activity have been proposed as promising strategies to treat chronic wounds [22].

We selected collagenase as model metalloproteinase to investigate cys-CNF interactions with this type of proteases. Collagenase incubation with cys-CNF for $24 \mathrm{~h}$ resulted in dose-dependent inhibition of the protease activity, reaching total inhibition when the material was assessed at the highest concentration (Figure $3 b$ ). To investigate the contribution of protein entrapment within the nanofiber network to the observed decrease in collagenase activity, protein concentration was evaluated after incubating the collagenase with cys-CNF for $24 \mathrm{~h}$. Results showed no protein entrapment with the lowest amount of cys-CNF and only $20-30 \%$ of the collagenase was retained when the highest amount of cys-CNF was assessed (Table 2). Thus, the main reason behind the observed decrease in collagenase activity is most probably the protease inactivation rather than just the entrapment of the protein within the fibril network. In this sense, it should also be noted that CNF alone (i.e., c-CNF) did not affect the activity of collagenase (Figure S2, Supplementary Materials).

Table 2. Entrapment of collagenase after incubation with the cys-CNF suspension (3.5 mg dry content).

\begin{tabular}{cc}
\hline Cys-CNF Sample & $\begin{array}{c}\text { Collagenase Entrapment } \\
\text { (\% of Control) }\end{array}$ \\
\hline$(1: 6)$ & $20 \pm 5$ \\
$(1: 20)$ & $30 \pm 5$ \\
\hline
\end{tabular}

It is expected that the sequestration of $\mathrm{Zn}^{2+}$ ions from the metalloproteinase active site would result in the inhibition of the protease activity [39]. Thus, the $\mathrm{Zn}^{2+}$-chelating capacity of cysteine [40] is most probably responsible for the observed decrease in collagenase activity after incubation with cys-CNF. Results of the $\mathrm{Zn}^{2+}$ binding assay showed that cys-CNF was able to bind $66 \pm 1 \%$ of the $\mathrm{Zn}^{2+}$ present in a solution incubated with the material in the same conditions as in the collagenase interaction study, while no ion binding was detected with c-CNF. Even though the material interaction with free zinc in solution cannot be directly compared with the access to zinc in a protein's catalytic center, the above results showed that cysteine did not lose its zinc binding capacity when incorporated into the CNF material.

\subsection{Material Stability over Time}

The instability of thiol-containing compounds toward self-oxidation in the presence of molecular oxygen is well known [41,42] and it could present a challenge for the bioactivity of the cys-CNF material. Even though the complete mechanism is yet to be established, selfoxidation of thiols by molecular oxygen seems to be dependent on $\mathrm{pH}$ and on the presence of transition metals that catalyze the reaction (i.e., present due to impurities) [41,42].

The thiol group content of cys-CNF and its radical scavenging activity were evaluated over a 30 day period. Results showed that when cys-CNF was stored as a gel suspension in close containers at $4{ }^{\circ} \mathrm{C}$, the thiol content decreased over time, showing $40-50 \%$ of the initial value 30 days after synthesis (Figure $4 \mathrm{~A}$ ). Even though the capacity of cys-CNF to inhibit the DPPH radical also decreased overtime, the observed loss in radical scavenging activity was less marked than the decrease in thiol content, with the remaining activity after 30 days representing $70 \%$ of the initial value (Figure $4 \mathrm{~B}$ ). 
A

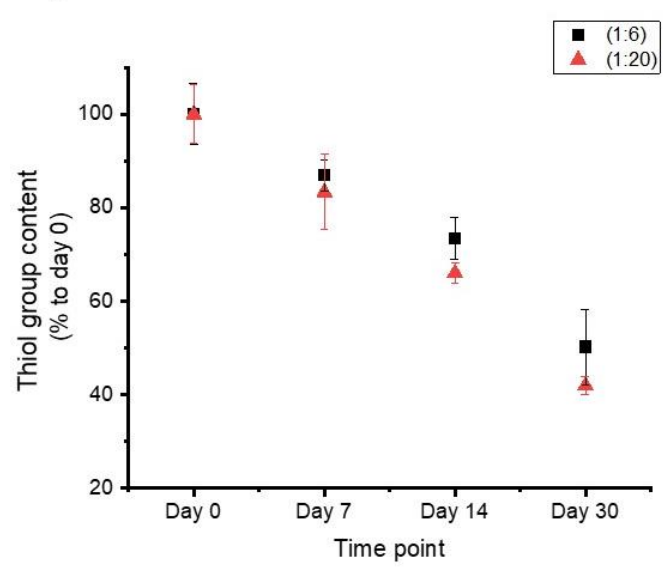

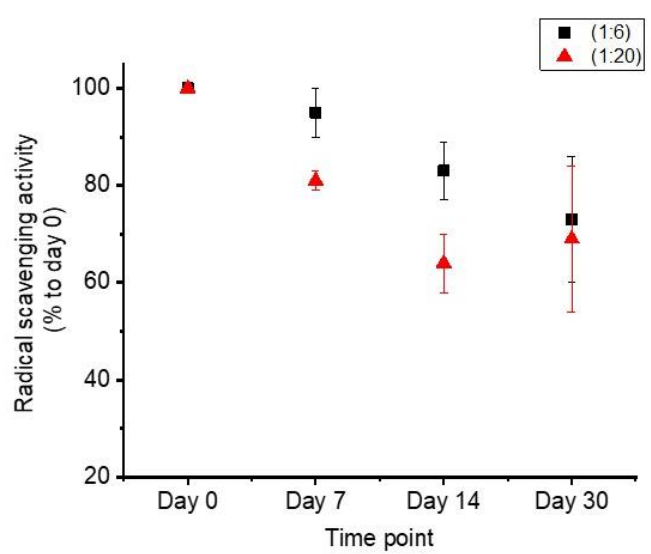

Figure 4. Stability of the thiol group in cys-CNF over time. (A) Thiol content measured with the Ellman assay, (B) radical scavenging activity assessed with the 1,1-diphenyl-2-picrylhydrazyl (DPPH) assay. Data are presented as mean \pm standard error of the mean of at least three independent experiments.

Two other storage conditions were evaluated in order to increase the thiol stability over time. To reduce the mobility of the fibers and thus hinder thiol-to-thiol encounters to form disulfide bonds, aerogels were prepared by freeze-drying the cys-CNF suspensions. Additionally, the cys-CNF suspensions were kept under an inert atmosphere to reduce the oxidation rate of the thiol groups. Both cys-CNF aerogels and the cys-CNF in inert atmosphere were more stable than the material stored in suspension (Table 3). Even though the reactivity of the thiol group poses a challenge to the shelf life of cys-CNF, alternative storage conditions such as inert atmosphere or aerogel form are valid approaches to increase the stability of the thiol groups in the cys-CNF material.

Table 3. Remaining thiol content (\%) in cys-CNF after 30 days of storage at different conditions.

\begin{tabular}{cccc}
\hline Cys-CNF Sample & $\begin{array}{c}\text { Suspension } \\
\text { (Air) }\end{array}$ & Aerogel & $\begin{array}{c}\text { Inert } \\
\text { Atmosphere } \mathbf{( N}_{\mathbf{2}} \text { ) }\end{array}$ \\
\hline$(1: 6)$ & $49 \pm 13$ & $67 \pm 19$ & $105 \pm 4$ \\
$(1: 20)$ & $43 \pm 8$ & $89 \pm 11$ & $76 \pm 4$ \\
\hline
\end{tabular}

\subsection{Cell Studies}

If intended to be used as a wound dressing, the safety profile of the thiol-functionalized CNF should be assessed. As a first screening, hDF, a well-established model system to study fibroblast response and wound healing, were selected to evaluate the in vitro toxicity of the cys-CNF material. The cytotoxic effects of cys-CNF (1:20) and c-CNF were evaluated by investigating the effect on cell metabolic activity and by microscopic evaluation of cell viability and morphology after exposure to the materials. Results showed that after $24 \mathrm{~h} \mathrm{ex}-$ posure to the CNF materials (concentration range $0.1-1 \mathrm{mg} / \mathrm{mL}$ ), the cell metabolic activity was above the 70\% cytotoxicity limit described by the ISO standard 10993-5 [43] (Figure 5). However, the highest concentration of cys-CNF induced a statistically significant decrease in cell metabolic activity compared with the negative control. Microscopy observations showed that the number of viable cells after exposure to the materials was comparable to the number of cells present in the negative control (non-exposed cells). Furthermore, the cell morphology was not affected by the exposure to increasing concentrations of cys-CNF or c-CNF, with cells maintaining the characteristic elongated shape of fibroblast cells in contrast with the round-shaped cells found in the positive control (Figure 6). 


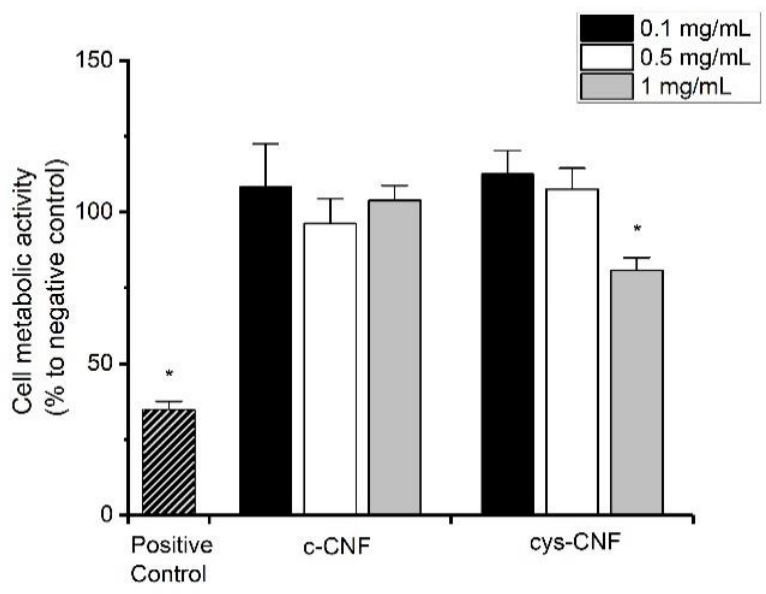

Figure 5. Cell metabolic activity of human dermal fibroblasts after $24 \mathrm{~h}$ exposure to cys-CNF and c-CNF suspensions. Data are expressed as percentage of the negative control (non-exposed cells) and presented as mean \pm standard error of the mean of at least three independent experiments. The positive control represents cells exposed to $5 \%$ DMSO. Significant results compared with the negative control are marked with * $(p<0.05)$.
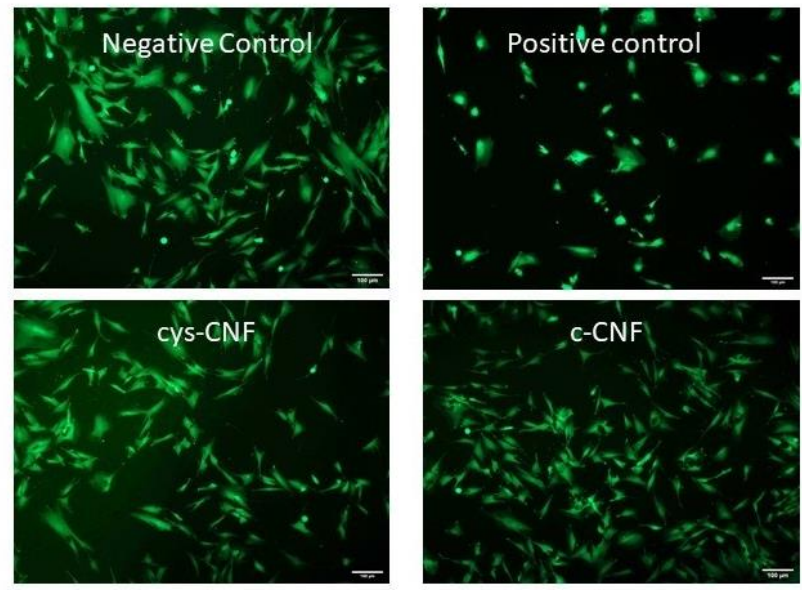

$0.1 \mathrm{mg} / \mathrm{mL}$
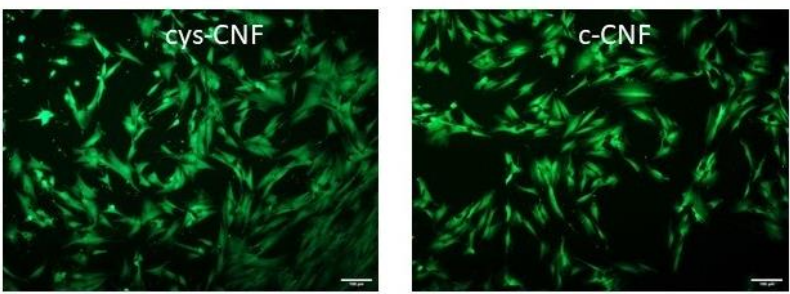

Figure 6. Representative images of calcein-AM stained human dermal fibroblasts after 24 h exposure to cys-CNF and c-CNF suspensions. The negative and positive controls were non-exposed cells and cells exposed to $5 \%$ DMSO, respectively. Scale bar represents $100 \mu \mathrm{m}$.

Overall, cys-CNF did not induce toxic effects on hDF when tested at a concentration up to $0.5 \mathrm{mg} / \mathrm{mL}$, nor did the starting material c-CNF. These results confirm the safety profile of nanocellulose fibers when in contact with biological systems, as previously investigated with different functionalized CNF materials and diverse cell models [44-47]. Future studies should investigate the in vitro wound healing capacity of cys-CNF in terms of dermal and epidermal cell response (proliferation, migration, and differentiation). 


\section{Conclusions}

In the present study, we showed that, by a well-known chemical approach, the amino acid cysteine was covalently incorporated into CNF endowing CNF with bioactivity toward the modulation of the chronic wound environment. The cys-CNF material presented a dual action in vitro: inhibition of metalloproteinase and radical scavenging activity, which are expected to contribute to the restitution of physiological conditions in the wound bed and promote the resolution of hard-to-heal wounds.

Supplementary Materials: The following are available online at https:/ / www.mdpi.com/2073-436 0/13/2/249/s1, Figure S1. (A) Representative SEM image of cys-CNF film with (B) its corresponding scanning of sulfur by SEM-EDS. Scale bar $1 \mu \mathrm{m}$; Figure S2. Collagenase assay kinetics. Representative data of the collagenase activity after incubation with cys-CNF and c-CNF. Control refers to collagenase incubated without CNF materials.

Author Contributions: Conceptualization, N.F.; Methodology, N.F., C.P.-N., J.L., and A.B.-R, Formal analysis, A.B.-R., C.P.-N., and N.F.; Investigation, A.B.-R. and C.S.; writing-original draft preparation, A.B.-R.; Writing-review and editing, N.F., M.S., C.S., J.L., and C.P.-N; Project administration, N.F.; Funding acquisition, N.F. All authors have read and agreed to the published version of the manuscript.

Funding: This research was funded by the Swedish Research Council (grant number 2018-04613) and Olle Engkvists Stiftelse (grant number 191-419).

Institutional Review Board Statement: Not applicable.

Informed Consent Statement: Not applicable.

Data Availability Statement: The data presented in this study are available on request from the corresponding author.

Acknowledgments: The authors would like to thank RISE Bioeconomy for supplying the nanocellulose material and Hasnae El Showk for valuable assistance with the cell studies.

Conflicts of Interest: The authors declare no conflict of interest. The funders had no role in the design of the study; in the collection, analyses, or interpretation of data; in the writing of the manuscript, or in the decision to publish the results.

\section{References}

1. Stadelmann, W.K.; Digenis, A.G.; Tobin, G.R. Physiology and healing dynamics of chronic cutaneous wounds. Am. J. Surg. 1998, 176, 26S-38S. [CrossRef]

2. Diegelmann, R.F.; Evans, M.C. Wound healing: An overview of acute, fibrotic and delayed healing. Front. Biosci. 2004, 9, 283-289. [CrossRef] [PubMed]

3. Hamdan, S.; Pastar, I.; Drakulich, S.; Dikici, E.; Tomic-Canic, M.; Deo, S.; Daunert, S. Nanotechnology-Driven Therapeutic Interventions in Wound Healing: Potential Uses and Applications. ACS Central Sci. 2017, 3, 163-175. [CrossRef]

4. Eming, S.A.; Martin, P.; Tomic-Canic, M. Wound repair and regeneration: Mechanisms, signaling, and translation. Sci. Transl. Med. 2014, 6, 265sr6. [CrossRef] [PubMed]

5. Jorfi, M.; Foster, E.J. Recent advances in nanocellulose for biomedical applications. J. Appl. Polym. Sci. 2015, 132, 132. [CrossRef]

6. Endes, C.; Camarero-Espinosa, S.; Mueller, S.; Foster, E.J.; Petri-Fink, A.; Rothen-Rutishauser, B.; Weder, C.; Clift, M.J.D. A critical review of the current knowledge regarding the biological impact of nanocellulose. J. Nanobiotechnol. 2016, 14, 1-14. [CrossRef]

7. Klemm, D.O.; Kramer, F.; Moritz, S.; Lindström, T.; Ankerfors, M.; Gray, D.G.; Dorris, A. Nanocelluloses: A New Family of Nature-Based Materials. Angew. Chem. Int. Ed. 2011, 50, 5438-5466. [CrossRef]

8. Lavoine, N.; Desloges, I.; Dufresne, A.; Bras, J. Microfibrillated cellulose-Its barrier properties and applications in cellulosic materials: A review. Carbohydr. Polym. 2012, 90, 735-764. [CrossRef]

9. Lin, N.; Dufresne, A. Nanocellulose in biomedicine: Current status and future prospect. Eur. Polym. J. 2014, 59, 302-325. [CrossRef]

10. Moohan, J.; Stewart, S.A.; Espinosa, E.; Rosal, A.; Rodríguez, A.; Larrañeta, E.; Donnelly, R.F.; Domínguez-Robles, J. Cellulose Nanofibers and Other Biopolymers for Biomedical Applications. A Review. Appl. Sci. 2020, 10, 65. [CrossRef]

11. Bacakova, L.; Pajorova, J.; Zikmundova, M.; Pajorova, J.; Kallio, P.; Kolarova, K.; Švorčík, V. Versatile Application of Nanocellulose: From Industry to Skin Tissue Engineering and Wound Healing. Nanomaterials 2019, 9, 164. [CrossRef] [PubMed] 
12. Tehrani, Z.; Nordli, H.R.; Pukstad, B.; Gethin, D.T.; Chinga-Carrasco, G. Translucent and ductile nanocellulose-PEG bionanocomposites-A novel substrate with potential to be functionalized by printing for wound dressing applications. Ind. Crop. Prod. 2016, 93, 193-202. [CrossRef]

13. Liu, J.; Chinga-Carrasco, G.; Cheng, F.; Xu, W.; Willför, S.; Syverud, K.; Xu, C. Hemicellulose-reinforced nanocellulose hydrogels for wound healing application. Cellulose 2016, 23, 3129-3143. [CrossRef]

14. Nordli, H.R.; Chinga-Carrasco, G.; Rokstad, A.M.; Pukstad, B. Producing ultrapure wood cellulose nanofibrils and evaluating the cytotoxicity using human skin cells. Carbohydr. Polym. 2016, 150, 65-73. [CrossRef] [PubMed]

15. Hakkarainen, T.; Koivuniemi, R.; Kosonen, M.; Escobedo-Lucea, C.; Sanz-Garcia, A.; Vuola, J.; Valtonen, J.; Tammela, P.; Mäkitie, A.; Luukko, K.; et al. Nanofibrillar cellulose wound dressing in skin graft donor site treatment. J. Control. Release 2016, 244, 292-301. [CrossRef] [PubMed]

16. Koivuniemi, R.; Hakkarainen, T.; Kiiskinen, J.; Kosonen, M.; Vuola, J.; Valtonen, J.; Luukko, K.; Kavola, H.; Yliperttula, M. Clinical Study of Nanofibrillar Cellulose Hydrogel Dressing for Skin Graft Donor Site Treatment. Adv. Wound Care 2020, 9, 199-210. [CrossRef]

17. Basu, A.; Lindh, J.; Ålander, E.; Strømme, M.; Ferraz, N. On the use of ion-crosslinked nanocellulose hydrogels for wound healing solutions: Physicochemical properties and application-oriented biocompatibility studies. Carbohydr. Polym. 2017, 174, 299-308. [CrossRef]

18. Basu, A.; Hong, J.; Ferraz, N. Hemocompatibility of Ca2+-Crosslinked Nanocellulose Hydrogels: Toward Efficient Management of Hemostasis. Macromol. Biosci. 2017, 17, 17. [CrossRef]

19. Basu, A.; Celma, G.; Strømme, M.; Ferraz, N. In Vitro and in Vivo Evaluation of the Wound Healing Properties of Nanofibrillated Cellulose Hydrogels. ACS Appl. Bio Mater. 2018, 1, 1853-1863. [CrossRef]

20. Basu, A.; Heitz, K.; Strømme, M.; Welch, K.; Ferraz, N. Ion-crosslinked wood-derived nanocellulose hydrogels with tunable antibacterial properties: Candidate materials for advanced wound care applications. Carbohydr. Polym. 2018, 181, 345-350. [CrossRef]

21. Basu, A.; Strømme, M.; Ferraz, N. Towards Tunable Protein-Carrier Wound Dressings Based on Nanocellulose Hydrogels Crosslinked with Calcium Ions. Nanomaterials 2018, 8, 550. [CrossRef]

22. Sabino, F.; auf dem Keller, U. Matrix metalloproteinases in impaired wound healing. Met. Med. 2015. [CrossRef]

23. Dunnill, C.; Patton, T.; Brennan, J.; Barrett, J.; Dryden, M.; Cooke, J.; Leaper, D.; Georgopoulos, N.T. Reactive oxygen species (ROS) and wound healing: The functional role of ROS and emerging ROS-modulating technologies for augmentation of the healing process. Int. Wound J. 2017, 14, 89-96. [CrossRef] [PubMed]

24. Kim, J.-H.; Jang, H.-J.; Cho, W.-Y.; Yeon, S.-J.; Lee, C.-H. In vitro antioxidant actions of sulfur-containing amino acids. Arab. J. Chem. 2020, 13, 1678-1684. [CrossRef]

25. Guidea, A.; Zăgrean-Tuza, C.; Mot, A.C.; Sârbu, C. Comprehensive evaluation of radical scavenging, reducing power and chelating capacity of free proteinogenic amino acids using spectroscopic assays and multivariate exploratory techniques. Spectrochim. Acta Part. A: Mol. Biomol. Spectrosc. 2020, 233, 118158. [CrossRef]

26. Wang, H.; Liu, R.; Liu, Y.; Meng, Y.; Liu, Y.; Zhai, H.; Di, D. Investigation on Adsorption Mechanism of Peptides with SurfaceModified Super-Macroporous Resins. Langmuir 2019, 35, 4471-4480. [CrossRef]

27. Rol, F.; Belgacem, M.N.; Gandini, A.; Bras, J. Recent advances in surface-modified cellulose nanofibrils. Prog. Polym. Sci. 2019, 88, 241-264. [CrossRef]

28. Chen, H.; Sharma, S.K.; Sharma, P.R.; Yeh, H.; Johnson, K.; Hsiao, B.S. Arsenic(III) Removal by Nanostructured Dialdehyde Cellulose-Cysteine Microscale and Nanoscale Fibers. ACS Omega 2019, 4, 22008-22020. [CrossRef]

29. Hernández, M.; Leyva, G.; Magaña, J.J.; Guzmán-Vargas, A.; Felipe-Mendoza, C.; Lara, V.; Lima, E. New copolymers as hosts of ribosomal RNA. BMC Chem. 2019, 13, 33. [CrossRef]

30. Nouvong, A.; Ambrus, A.M.; Zhang, E.R.; Hultman, L.; Coller, H.A. Reactive oxygen species and bacterial biofilms in diabetic wound healing. Physiol. Genom. 2016, 48, 889-896. [CrossRef]

31. Comino-Sanz, I.M.; López-Franco, M.D.; Castro, B.; Pancorbo-Hidalgo, P.L. Antioxidant dressing therapy versus standard wound care in chronic wounds (the REOX study): Study protocol for a randomized controlled trial. Trials 2020, 21, 1-9. [CrossRef] [PubMed]

32. Xu, Z.; Han, S.; Gu, Z.; Wu, J. Advances and Impact of Antioxidant Hydrogel in Chronic Wound Healing. Adv. Health Mater. 2020, 9, 1901502. [CrossRef] [PubMed]

33. Moseley, R.; Leaver, M.; Walker, M.; Waddington, R.; Parsons, D.; Chen, W.; Embery, G. Comparison of the antioxidant properties of HYAFF ${ }^{\circledR}-11$ p75, AQUACEL ${ }^{\circledR}$ and hyaluronan towards reactive oxygen species in vitro. Biomaterials 2002, 23, $2255-2264$. [CrossRef]

34. Moseley, R.; Walker, M.; Waddington, R.J.; Chen, W. Comparison of the antioxidant properties of wound dressing materialscarboxymethylcellulose, hyaluronan benzyl ester and hyaluronan, towards polymorphonuclear leukocyte-derived reactive oxygen species. Biomaterials 2003, 24, 1549-1557. [CrossRef]

35. Ataide, J.A.; De Carvalho, N.M.; Rebelo, M.D.A.; Chaud, M.V.; Grotto, D.; Gerenutti, M.; Rai, M.; Mazzola, P.G.; Jozala, A.F. Bacterial Nanocellulose Loaded with Bromelain: Assessment of Antimicrobial, Antioxidant and Physical-Chemical Properties. Sci. Rep. 2017, 7, 1-9. [CrossRef] 
36. Morais, E.S.; Silva, N.H.; Sintra, T.E.; Santos, S.A.; Neves, B.M.; Almeida, I.F.; Costa, P.; Correia-Sá, I.; Ventura, S.P.M.; Silvestre, A.J.D.; et al. Anti-inflammatory and antioxidant nanostructured cellulose membranes loaded with phenolic-based ionic liquids for cutaneous application. Carbohydr. Polym. 2019, 206, 187-197. [CrossRef]

37. Cullen, B.; Watt, P.W.; Lundqvist, C.; Silcock, D.; Schmidt, R.J.; Bogan, D.; Light, N.D. The role of oxidised regenerated cellulose/collagen in chronic wound repair and its potential mechanism of action. Int. J. Biochem. Cell Biol. 2002, 34, 1544-1556. [CrossRef]

38. Mccarty, S.M.; Percival, S.L. Proteases and Delayed Wound Healing. Adv. Wound Care 2013, 2, 438-447. [CrossRef]

39. Jacobsen, J.A.; Jourden, J.L.M.; Miller, M.T.; Cohen, S.M. To bind zinc or not to bind zinc: An examination of innovative approaches to improved metalloproteinase inhibition. Biochim. Et Biophys. Acta (BBA)-Bioenerg. 2010, 1803, 72-94. [CrossRef]

40. Pace, N.J.; Weerapana, E. Zinc-Binding Cysteines: Diverse Functions and Structural Motifs. Biomolecules 2014, 4, 419-434. [CrossRef]

41. Benesch, R.E.; Benesch, R. The Acid Strength of the -SH Group in Cysteine and Related Compounds. J. Am. Chem. Soc. 1955, 77, 5877-5881. [CrossRef]

42. Bagiyan, G.A.; Koroleva, I.K.; Soroka, N.V.; Ufimtsev, A.V. Oxidation of thiol compounds by molecular oxygen in aqueous solutions. Russ. Chem. Bull. 2003, 52, 1135-1141. [CrossRef]

43. Part 5: Test for in vitro cytotoxicityIso. In Iso 10993-5: Biological Evaluation of Medical devices; ISO: Geneva, Switzerland.

44. Lopes, V.R.; Sanchez-Martinez, C.; Strømme, M.; Ferraz, N. In vitro biological responses to nanofibrillated cellulose by human dermal, lung and immune cells: Surface chemistry aspect. Part. Fibre Toxicol. 2017, 14, 1-13. [CrossRef]

45. Lopes, V.R.; Strømme, M.; Ferraz, N. In Vitro Biological Impact of Nanocellulose Fibers on Human Gut Bacteria and Gastrointestinal Cells. Nanomaterials 2020, 10, 1159. [CrossRef] [PubMed]

46. Čolić, M.; Mihajlović, D.; Mathew, A.P.; Naseri, N.; Kokol, V. Cytocompatibility and immunomodulatory properties of wood based nanofibrillated cellulose. Cellulose 2015, 22, 763-778. [CrossRef]

47. Alexandrescu, L.; Syverud, K.; Gatti, A.; Chinga-Carrasco, G. Cytotoxicity tests of cellulose nanofibril-based structures. Cellulose 2013, 20, 1765-1775. [CrossRef] 